\title{
Non-linear discourse and control of technology: The Pharmaceutical Society and poisons legislation in nineteenth century Britain
}

\begin{abstract}
The Pharmaceutical Society of Great Britain was established in 1841 to represent the interests of its members, many of whom were small chemist and druggist retailers. Throughout the century this institution attempted to influence new policies designed to control the sale of poisonous substances routinely held by these shopkeepers. Using its in-house publication, the Pharmaceutical Journal, the Society argued for recognition of chemists and druggists as experts in the storage and distribution of poisons. This article examines the discursive strategy adopted by the Pharmaceutical Society in its attempts retain control over sale of chemicals. Its activities are analysed both in respect to the complex and socially embedded nature of chemical products, and to the technocratic nature of its claims.
\end{abstract}

\section{Keywords}

Socio-technical complexity, poisons legislation, Pharmaceutical Society, discursive strategy

Dr Anne-Marie Coles, Senior Lecturer, Department of Systems Management and Strategy, Faculty of Business, Greenwich University, Old Royal Naval College, Park Row, London SE10 9LS; e-mail: A.Coles@gre.ac.uk; 
The Royal Pharmaceutical Society of Great Britain was established in 1841 to publically represent the interests of its members, mainly small chemist and druggist shop owners. During the course of the nineteenth century, the Society took a particular interest in policy debates aimed at regulating the sale of poisonous substances. Throughout the century the Society utilised its inhouse publication, the Pharmaceutical Journal to publish rhetorical statements regarding the expertise of its members in dispensing and distributing highly toxic chemicals for household use. The Society launched a campaign to be recognised as the authentic source of technical knowledge that could best control unwanted social effects of poisons. The aim was to draw clear boundaries between those with technical knowledge and the wider public, as well as between different scientific disciplines. Strategic discourse was used to persuade the public to accept its authoritative expertise. This defence was necessary due to the distributed nature of chemist and druggist retail establishments, which stocked the substances under debate. In addition many of these chemicals were embedded in everyday household practices and were expected to be generally available to the public. These complex socio-technical configurations provided a difficult context for control of problematic substances. Not only was there a wide variety of chemicals available, for many substances there was also a lack of documented knowledge on safe handling beyond traditional practice.

Discursive activities of the Society, aimed at exerting a strong influence on the content of new policy, calls into question assumptions that regulation technologies in the nineteenth century was necessarily technocratic in nature. This article will evaluate the role taken by the Pharmaceutical Society in the process of policy formulation until the passage of the Pharmacy Act 1868. It 
attempts to draw together theoretical concepts relating to the complexity and inflexibility of embedded socio-technical practices with a re-evaluation of the role of deliberative processes in policy formation in nineteenth century Britain. It is suggested that, in cases of sociotechnological complexity, participation in public policy formulation is strategic, argumentative and negotiated rather than rationalistic and conferred. Furthermore, identifying non-linearity in public discourse serves to elucidate how powerful interest groups attempt to influence the social control of technology.

\section{Complexity and chemical technologies}

Kim (2008) identifies the socially entrenched nature of chemical technologies and highlights difficulties involved in making changes to technologies that are commonplace in daily life. Kim suggests that the distributed nature of these technologies render them inflexible and resistant to change, for example in relation to changing policy priorities. It is suggested here that such inflexibility is, in fact, an outcome of complexity of the socio-technical configurations associated with use of easily available chemical products (for further discussion on the nature of inflexible technology see Collingridge, 1980). As Kim points out,

'Once technology is socially entrenched, policy makers who want to either withdraw it or transform it must take into consideration the inflexibility of heterogeneous technosocial systems entangled with the technology. If technology is seen to be highly inflexible, policy makers need to exercise policy practices that do not provoke a severe repulsion from existing technosocial systems. They should have policy tools that are able to expedite policy practices without enormous resistance from affected systems linked to 
inflexible technologies’ (Kim, 2008: 463).

It should be noted that Kim is referring here to current technologies which are organic in nature. Chemical products in the nineteenth century were predominantly inorganic, although these were also entrenched in everyday practice. In addition, many of the readily available substances had been in common use for generations and were easily available from local chemist and druggist shops. Passage of the Pharmacy Act 1868 was an attempt to change the status quo and to control sale of toxic substances commonly associated with criminal and accidental poisoning. Identifying the inflexibility of complex relationships within a socially entrenched technology raises the problem of controlling risks that emerge from the very practices that embed the technology (Coles, 2010). As Kim (2008) points out understanding the impetus for improved control over such substances could reveal key issues in the process of social embedding and reembedding of technologies (see also Genus, 1995, 1997).

Confronting complexity in socio-technical practices raises a question about the use of complexity concepts in qualitative analysis. Terms such as ‘self-organization' and 'emergence’ are already widespread while others such as ‘turning point', ‘bifurcation’ and ‘non-linearity’ still require clarity in their application to qualitative analysis. Mackenzie (2005: 49) calls this transfer of terminology a 'loose metaphorical borrowing' by the social sciences. Hearn et al. (2003) describes qualitative changes to knowledge systems as 'turbulent' (see also Byrne, 2005). Urry (2002) argues for the adoption of complexity concepts by social sciences to focus attention on explaining specific social or systemic phenomena. For Urry (2005: 243) processes of social change are uneven, non-linear, unpredictable and irreversible, with emergent properties that 'stem from how agents interactively respond to local configurations'. Particular interactions also 
influence the probability that later events will take place (see also Geyer, 2003; Nowotny, 2005).

The dynamism and turbulence which describe the development of socio-technical configurations has led other commentators to suggest a historical analysis is necessary to identify the main determinants of change (Hirsch and Gillespie, 2001). The case presented here concerns the nature of fundamental social changes that were made to control availability of poisonous substances in the nineteenth century. The article focuses primarily on identification of how public discourse published by the Pharmaceutical Society could be interpreted as non-linear over time. Following turns in the arguments put forward by the Society reveals its strategic response to different iterations of proposed policies. These responses were altered in reaction to the unfolding situation. Both conditions of uncertainty regarding outcomes and non-linear responses arise from the socio-technical complexity of the situation. This also helps to explain why the Society needed to argue so forcefully for its expertise to be publically recognised.

\section{The relationship between rhetoric and technocracy}

Analysis of this historical episode will also contribute to understanding the nature of policy making to control socially embedded technologies. Millstone (2009) has pointed out that, in the second half of the twentieth century, the dominant model of policy for science and technology in Europe has been technocratic. This approach, he states assumes 'that scientific and technical considerations are not just necessary but also sufficient for policy decision-making' (Millstone, 2009: 625). Technocratic policy making demands that policies should be evaluated and decided by experts who can then advise on the appropriate course of action. This implies that a politically neutral and objective expertise is of greater relevance to policy makers than input and commentary by specific interest groups. For Millstone technocratic decisions are based on an 
unexamined rhetoric of non-controversial scientific and technological knowledge, which also applies to policy making processes in the nineteenth century. Mulkay (1993) discusses the use of rhetorical positions in policy debate and identifies contradictory positions proposed by different interest groups in relation to decision making over the 'embryo debate'. Even in a technocratic context, then, alternative rhetorics are possible (see also McNally, 2000). In addition, other public policy commentators have explored the use of rhetoric as a strategic tool for communicating a preferred interpretation of events (Americ, 2004). In public policy debates rhetorical strategies have been used as a means to frame issues and establish credentials, reputation or position. As Jeriti (2008) asserts the aim is to be entrusted with ownership of an issue. Dunmine (2005: 482) examines the way in which discursive processes can act to embed a future scenario in the present, creating potential representations, visions, or a 'contested rhetorical domain'. Rhetoric therefore is understood as a political discourse which makes claims, assertions and declarations about future realities, or a future projected and represented. This article investigates how such 'authoritative expertise’ was established by the Pharmaceutical Society in its attempts to influence policy and endeavours to reveal its discursive and strategic characteristics.

Lengwiler (2008) suggests that a better understanding of the role of participation in policy formulation can be gained from historical analysis of changing relations between science, technology and government. Such an approach, he asserts helps to locate the dominant technocratic system as relatively recent, with precursor systems acting much more interactively. Lengwiler further claims that technology policies in the nineteenth century primarily demonstrated a concern to draw boundaries between science, technology and the wider public. 
Claims for expertise were often made by newly emerging professional societies and institutions,

'The actors of nineteenth century science were more concerned with drawing a clear boundary between the spheres of science and the public or between scientific and lay or religious knowledge, a process that parallels the secularization of natural knowledge' (Lengwiler, 2008:189).

Both Millstone and Lengwiler suggest that establishment of, and change in, policy regimes have a discursive element in which favoured relations between science and the state are strategically and dynamically pursued by interested groups. Their approach implies that roles and boundaries are negotiated, and stabilised although this stability may be challenged and boundaries redrawn (see Genus and Coles, 2005). These processes can be interrogated through a historical analysis of policy development which focuses on issues of context and contingency of participants and events. By identifying discursive episodes it is possible to reconstruct how rhetorical claims to expertise have become accepted unconditionally. Jensen (2005) refers to the potential to 'open up' the past particularly during episodes of re-description of established practices, which echoes Cilliers (2005) view that understanding complex socio-technical processes is facilitated by their deconstruction rather than their reduction to limiting frameworks. As he suggests, 'meaning and knowledge cannot be fixed in a representational way but is always contingent and contextual' (Cilliers, 2005: 259). Thus it is suggested that emergence of a technocratic idiom in policy decisions may not be the logical outcome of a system predicated on the acceptance of objective recommendations from legitimate experts. Rather, it is a discursive and negotiable outcome to a policy issue which has itself been framed by the socio-technical contingency and complexity of a situation. Far from being a rationalistic enterprise predicated on the objectivity of authenticated 
techno-scientific knowledge, communicative interactions are made by interest groups aimed at drawing boundaries between their expertise and the public. Such boundaries are partly discursively constructed, negotiated through public communicative practices and permeable to 'non-experts'. The following sections attempt to examine how such processes have been utilised in the particular case of the Pharmaceutical Society as it strategically defended the interests of its members. Firstly, an outline will be given to the social context which led to call for new policies to regulate the availability of known poisons. The rhetorical response of the Society will then be considered in the light of its strategic ambitions.

\section{The social role of poisonous substances in nineteenth century Britain}

Many chemicals were generally available in the nineteenth century as such substances were constituents of many standard products available for domestic use. These ranged from relatively benign to highly toxic substances, for example opium and hydrogen chloride were commonly prescribed for medicinal use, while arsenic was widely used as a food colouring. Although there was some governmental concern about the high number of deaths arising from the unfettered availability of such substances, they were also regarded as socially and economically difficult to

control. During the century chemist and druggist retailers grew in local importance. These shops were becoming an established part of local communities, dispensing medicinal preparations, and offering medical advice to their customers. Their economic and advisory roles gave them a high standing in the community, and during the century the number of chemist and druggist shops started to increase over the country (Marland, 1987). By the mid-nineteenth century they had established themselves as traders supplying general household chemical goods as well as dispensing a range of medical preparations. However, chemist and druggist enterprises were 
differentiated in both size and scope. They ranged from all-purpose corner shops to large undertakings with wholesale and manufacturing capability more concerned with supplying dedicated medicinal preparations than general commerce. The nature of their specialisation in chemical and pharmaceutical products resulted in a protracted struggle to attain a recognised position as part of the emerging medical profession (Holloway, 1991). The typical stock of a chemist and druggist could include pharmaceutical preparations, toiletries, tobacco, herbs, oils, candles, dyes and paints as well as general groceries and foodstuffs. Animal remedies and other veterinary goods were supplied and in some cases dentistry practices were carried out at the premises (Homan, 2005). In some shops manufacture of medicinal goods and other chemical substances was common practice, and part of the premises was converted into a chemical laboratory. These activities necessitated a dedicated storage area for substances which were kept in large glass bottles, in many cases with no discrimination between lethal and less harmful substances (Worling, 2005). As Holloway (1991: 52) notes, proprietors ‘had to be prepared to practice a wide range of medical skills and to sell a diversity of products'.

During the nineteenth century these establishments became vulnerable to changing social attitudes, particularly concerning the easy availability of the more toxic substances that they distributed. In addition, the role they played in dispensing medicinal preparations to the local community put chemists and druggists in competition with the established profession of the apothecary. As early as 1813 local associations of chemists and druggist were set up to oppose legislation that would restrict this aspect of their business. However, these organisations were small and lacked co-ordination until the establishment of the Pharmaceutical Society in 1841. As a national organisation this body had clear policies to develop the professional and defend the 
economic activities of this sector. The Society increased in political influence during the century as it developed into an organisation that was regarded as representative of the general trade, due partly to the public efforts of one of the founder members, Jacob Bell (Holloway, 1991). From its inception the Council of the Pharmaceutical Society was concerned with defending the interests of members against unwanted legislation that would affect the sale of chemicals.

During the first half of the nineteenth century the question of criminal use of poisons became a cause for public concern, which led to repeated suggestions that these substances should be controlled by parliamentary legislation. Development of the Marsh test in 1836 which identified the presence of small quantities of arsenic in biological matter focused attention on this substance. The Marsh test appeared to provide a means to obtain conclusive indication that arsenic was the cause of poisoning fatalities. However, there were on-going problems with its deployment in legal prosecution as results were often difficult to interpret. Such uncertainty coupled with the on-going moral panic led to parliamentary action in the form of the Arsenic Act 1851. This legislation was intended to protect the public against fatalities from improper use by documenting all sales, providing a means of tracing customers, and restricting sale to small quantities for domestic use (Bartrip, 1992). However, as arsenic was only one of many potentially lethal substances, there was on-going concern that more general legislation was necessary. The response of the Pharmaceutical Society to growing public concern over the issue of poisoning from chemical products and the stated intention that these were to become the subject of new policy regulations can be divided into three phases. The first was prior to the Arsenic Act, in which the strategic goals for the Society were set down and agreed. The second between 1851 and 1868 when the Society argued publicly to be recognised as the source of 
expertise in the issue of chemical safety at the point of sale, and a third phase in the years subsequent to the Pharmacy Act 1868, when the Society drew attention to statistics that appeared to confirm their successful administration of the new policy arrangements.

\section{Strategy formulation}

Prior to 1851 the Society spent some effort on developing its specific approach to the problem of widely available, yet toxic chemical products. It devised a strategy for policy control that took into account issues of concern to its members and would give administration of new regulations to the Society itself. A statement of objectives was made and these aims were reported as a clear and rational means of control. They were defended and reiterated through the pages of the Society’s own publication, the Pharmaceutical Journal until they were finally achieved. The first point was to retain support for continued availability of all substances traditionally purchased in chemists' shops. This point was based on the economic necessity of such chemicals and on the argument that chemists should be regarded as having the expertise to control supply. The Pharmaceutical Society supported availability of such substances because of their commercial value, especially in agricultural districts where they were in general use (Anon (a), 1844/5). It was felt that the main problems facing a new policy for control was the difficulty of defining which substances should be considered poisons and their commercial importance,

Many tons of arsenic and sulphate of copper are annually employed for agricultural purposes. Many other highly deleterious substances are extensively used in the arts and manufactures and although every precaution ought to be taken to avoid accidents in the use of these articles, the prohibition of their sale, even if practicable, would be attended 
with very serious commercial inconvenience (Anon (b), 1844/5: 341).

One issue was potential resistance of the public to changes in the availability of commonly used remedies, as the British public 'would be indignant if they could not take a calomel pill or a dose of James’ powder without consulting a doctor' (Ibid: 346). The scope of the problem was illustrated by the fact that between 1837 and 1838 more than one third of all cases of poisoning were estimated to have been caused by arsenic (Anon (c), 1849/50). Other known poisons in common use included oxalic acid, salts of sorrel, salts of mercury, copper, lead, potassium cyanide, iodine, and oil of vitriol. The Pharmaceutical Journal suggested that the word poison should be marked on such substances to acquaint the purchaser of its properties. They could be distinguished by being kept in blue bottles, and marked 'for external use only'. Remedies which could not be sold through a physician should carry notification of prescribed doses (Anon (d), 1844/5). However, growing public alarm relating to the use of arsenic in murder cases forced the Society to articulate support for specific regulation of this substance, reiterating the key role of the retailers,

We fully agree.... That much difficulty and inconvenience would attend the introduction of a comprehensive law for restricting the sale of poisons generally; but if we may judge from the cases of poisoning reported almost daily in the public papers, there are good grounds for believing that a proper restriction on the sale of arsenic by retail would be the means of preventing at least nine-tenths of the criminal poisoning which now occur (Anon (e), 1847/8: 142). 
The focus on arsenic was a tactical move away from earlier pronouncements on general control of poisons in response to increasing public pressure for a specific policy for this particular substance. In part, it was a response to, and an acknowledgement of, the wider social disquiet that had been developing over the use of arsenic in so-called cases of 'secret poisoning'. These concerns had been fuelled in part by publicity surrounding problems with using the Marsh Test in high profile murder cases (Bartrip, 1992). The Pharmaceutical Journal noted:

In consequence of the numerous cases of secret poisoning which have lately become public, a variety of plans have been suggested with a view of placing some check upon this destructive crime (Anon (c), 1849/50: 160).

There was also growing awareness that cheap cost, easy availability and range of common domestic uses were contributing to the increasing use of arsenic in suicide cases and accidental poisoning. During the 1840s the Registrar General continually attributed one third of such fatalities to arsenic (Holloway, 1991). The issue of arsenic had clearly disassociated itself from more general concerns regarding stocking and retailing other potentially lethal substances. These developments enabled the Society to put forward the second plank of its preferred strategy for control, introduction of an Act of Parliament to regulate the qualifications of chemists and druggists. Such an Act, it was suggested, would ensure that most lethal poisons were kept separately, and substances would be labelled correctly (Anon (f), 1848/9). The Society expected chemists would oppose moves to control arsenic on commercial grounds, and because of fears that such a law might be inoperative. They could also object to singling out just one poison, as was noted in the Pharmaceutical Journal, 
Accidental poisoning is overlooked, the education and examination of those who deal in poisons is deemed a matter of no moment, and opium, aconite, lobelia, hemlock and nightshade, with a thousand other deadly drugs, may be sold without restraint by ignorant persons, provided always that a prohibition is placed on the sale of arsenic by granting a licence to sell it (Anon (c): 163).

In an early example of strategic co-operation, however, the Pharmaceutical Society, acting jointly with the Provincial Medical and Surgical Association, set up a committee to consider the practicability of adopting measures for preventing accidental and criminal poisoning (Anon (g), 1849/50), although it was noted,

It was not to be expected that all parties would at once acquiesce in the property of legislative enactment interfering in some degree with their business arrangements, still less was it to be expected that all would agree as to precise nature of the regulations most calculated to produce the desired effect (ibid: 297).

It subsequently became clear that many members of the Society had already adopted similar practices to those being considered. A meeting between the committee of the Provincial Medical and Surgical Association and the Committee of the Pharmaceutical Society managed to agree on a common definition of the problem, which suited the two institutions, 'to confine recommendations to arsenic, enshrining the role of the retail trade, as the sale of arsenic retail should be restricted to medical men and chemists and druggists' (ibid: 452). It was resolved to 
send the recommendations to the Secretary of State, and noted that this had also been done by the Provincial Medical and Surgical Association. The Earl of Carlisle introduced the first reading of the Bill to Regulate the Sale of Arsenic in March 1851, in the hope that debate would be limited to avoid publicising potential criminal uses of the substance. However, the two Societies continued to pressure Lord Carlisle until the, Bill was amended to reflect their joint recommendations. The Arsenic Act received Royal Assent in June 1851 (Bartrip, 1992). On reflection the Pharmaceutical Society felt that the policy of co-operation had been better than the two Societies opposing each other on practical grounds, although it was still concerned that the Act would be inoperable until there was a means of defining and regulating the quality of chemists and druggists (Holloway, 1991).

\section{Influence of the Pharmaceutical Society on the control of poisons 1851-1868}

The need to control availability of other poisons besides arsenic was soon raised as an issue. However, problems were identified, both of defining which substances were poisons, and of deciding which of these should be restricted. The Pharmaceutical Society suggested one of two approaches could be chosen:

If the sale of poisons is to be dealt with by law, then the law must either give a list of the poisons to which it applies, in which case it must be a law for regulating the sale of certain poisons, or it must give a definition of what a poison is, and leave it to the discretion of the retailer to decide what drugs fall under that category (Bath, 1856: 258).

Clearly the Society was highlighting the issue of utilising appropriate knowledge and expertise 
and offering the choice between a static but legal definition via a negative list or a more interpretive definition based on expert assessment. A Sale of Poisons Bill was introduced in 1857, but it did not meet with support of the profession as it made no distinction between qualified and unqualified chemists (Anon (h), 1857/8). Expanding the terms of control at the point of sale to a wider range of substances meant a return to the issue of qualifications. The Pharmaceutical Society stated that it,

Had always advocated judicious legislation on the sale of poisons and medicines generally, but maintained that, unless judicious, and in the right direction, legislation was likely to increase the evil by directing attention to the subject and also by removing the existing responsibility from the vendors of drugs (Anon (j), 1857/8: 417).

The Society was also vocal against potential legislation that affected chemists alone warning that:

The morbid nervousness which prevails at the present time about the public safety leads its votaries into some rather strange inconsistencies. The true and legitimate object of the poisons bill is to protect the public in England against injury arising from crime and carelessness in the use of dangerous drugs. Patent medicines are excluded from the operation of the Bill yet many of these contain powerful and poisonous ingredients in a form very convenient for the criminal and liable to accident in the hands of careless persons (ibid: 201). 
It was suggested that lack of standard prescriptions would leave untrained chemists to worry about poisonous dose levels. Drawing a contrast with a wider public who were thought to be uninformed and therefore ignorant of the nature of such substances they might purchase was one way of making the issue plain,

It appears from the tenor of information received that the public are fortunately ignorant of the nature and mode of employment of poisons in general as such, and the committee doubt very much the policy of extending this knowledge by the publication of a long schedule of poisons with various particulars of a suggestive nature in the accomplishment of this object: While on the other hand, the chef security of the public consists in the discretion and intelligence of the qualified vendor of poisons, who in self defence, as well as from higher motives is constrained to adopt precautions which no Act of parliament could define so completely as to constitute a safeguard equal to the moral responsibility now existing (ibid: 452).

The Society objected to the establishment of a poisons schedule which had been recommended both by the Board of Health and by medical practitioners, but favoured the idea that a Board of Examiners should be set up to examine and license pharmaceutical chemists. It considered that the attempts at legislation, passing through the House of Lords only betrayed ignorance of such matters,

Their Lordships had probably never entered a laboratory; certainly they had never discharged the duties of assistants in a Chemists shop or they would not betray so much 
ignorance on what they were legislating (ibid: 441).

Opposition to the 1857 Bill by the Pharmaceutical Society resulted in its modification and agreement to set up a Board of Examiners creating a new qualification - the 'Licensed Druggist'. However the Society objected to the fact that the board of six examiners was only to have one representative from pharmacy (Anon (j), 1898). This Bill was eventually withdrawn, although in 1858 an amended Sale of Poisons Bill was introduced which included a schedule of poisons. This was also defeated in part due to communications from the Pharmaceutical Society. However, legislation was felt to be necessary, and it was noted,

While the areas of poisoning by arsenic had so much decreased in number, deaths from other poisons had become considerably more frequent (Anon (k), 1858/9:483).

In 1864 two Bills were promoted regarding the registration of chemists and druggists. The United Society of Chemists and Druggists wanted control over the sale of certain poisons while the Pharmaceutical Society wanted to restrict the compilation of prescriptions to registered chemists and druggists. The House of Commons Select Committee suggested that the two should present a more untied front before a new Bill could be introduced (Anon (j), 1898). In addition, the growing realisation that poisoning remained a social problem resulted in support for the examination and registration of qualified chemists and druggists. Sir John Simon, Medical officer to the Board of Health, had requested a report investigating the competencies of persons retailing drugs and poisons, which highlighted lack of regulation and training. In response, Simon gave his support to the Pharmaceutical Society to become an 'exclusive, regulatory 
organisation under the close supervision of the Privy Council’ (Holloway, 1991: 230). This support gave a favourable context for the Society's amended Bill (supported by the United Society of Chemists and Druggists) to regulate the sale of poisons and alter and amend the Pharmacy Act 1852, which was introduced to the House of Lords in May 1868. The Bill was steered by the Liberal politician, Lord Granville who was both a supporter of the Pharmaceutical Society and a friend of John Simon (Holloway, 1991). Supporters of the Bill hoped for easy progress through parliament and the House of Lords debate on the third reading on June 8th was relatively uncontested. A suggestion by Lord Redesdale that poisons should be stored in an easily recognised 'poisons bottle’ was rejected. The gave the Duke of Marlborough opportunity to voice his support for the Pharmaceutical Society’s expertise, as he felt it would be better 'to leave it to the discretion of the Pharmaceutical Society and the Privy Council to take what precautions they thought necessary against the careless sale of poisons’ (Hansard, 1868a). A more intense debate was raised in the House of Commons due mainly to the interjections and amendments from Robert Lowe who wanted to see the Privy Council's role strengthened in administering any legislation. In particular, he wanted an amendment which would enable the Privy Council to propose regulations for keeping, dispensing and selling poisons. However, this suggestion was rejected in favour of leaving these activities with the Pharmaceutical Society (Holloway, 1991). Support for the expertise of the Society in its knowledge of poisons was demonstrated again when Lowe proposed that restrictions introduced in the Arsenic Act should be applied to all poisons. Lord Elcho, who was sponsoring the Bill in the House of Commons, felt that these restrictions were too stringent and replied,

(the) Pharmaceutical Society—a body of gentlemen in daily practice, and to whom (lie 
(sic) public were under great obligations — considered requisite, establishing, as it did, the proper medium between drawing the law so tightly that it must break in their hands and that laxity which would be prejudicial to the whole community. He was informed that the Arsenic Act was too stringent, and was practically a dead letter (Hansard, 1868b)

The Pharmacy Act received Royal Assent in July 1868, required that all chemists must submit to registration, and the sale of poisons was restricted to qualified persons. The Pharmaceutical Society was in agreement, as they had,

Ever endeavoured to raise their status by enforcing a better qualification, to maintain it and by promoting that union among them which has now been accomplished after many years of anxious exertion (Anon (l), 1868/9: 49).

The Act set up the Poisons Schedule, a list of substances that were to be treated as potentially lethal. The Council of the Pharmaceutical Society could make a resolution for any substance to be added to the list and submit it to the Privy Council for approval. It would then be advertised in the London and Edinburgh Gazettes, and after one month it became a scheduled poison under the Act. Poisons were to be labelled with the name and address of the vendor, sales were to be entered on a register, and certain substances could only be sold to persons known to the seller. The Pharmaceutical Society was charged with the administration of the Act and the examination and registration of chemists (ibid). There had been some pressure within the House of Commons for the role of the Privy Council, as a government department, to be extended over the role of the Pharmaceutical Society, who was thought to have only the welfare of small traders at heart. This 
was not a popular move, however, as the Pharmaceutical Journal noted,

... What is proposed is to get rid of the Pharmaceutical Society in this matter, and then to enact that another gentleman, the medical officer of the Privy Council, for that will be the effect of it, shall by his own ipse dixit declare what is a poison and what is not (ibid: 58).

The services of the Pharmaceutical Society were retained, as was the approach of compiling a negative list of substances,

Some critics have chosen to call it absurd to select just thirteen poisons for legislation and leave vastly larger numbers unfettered. We would remind them that the object was to restrict those articles most commonly used for criminal purposes, and to impose as little inconvenience as might be on the trade (Anon (m), 1869/70: 315).

\section{The Pharmaceutical Society's review}

The Pharmacy Act 1868 finally resolved the issue of whom should be in control of supplying potentially toxic substances to the public. The Pharmaceutical Society was careful to defend the status quo which had tipped the balance in its favour. In 1891, keen to show the system was working successfully, the Society published some statistics. Of 876 deaths by poisoning in that year, 544 of these were accidental, and accounted for 3.25\% of all deaths by accident. The largest proportion was from narcotic poisons, (114 or 21\% of the total), 48 (9\%) by carbolic acid and mineral acid, 2 by oxalic acid, 8 by arsenic and 7 by chloral. In addition, 16\% were found to be caused by articles not on the poison schedule (Anon (n), 1892/3: 611). The problems of 
definition were still not overcome, however,

The question as to the quantity of a poison by which a preparation becomes a poison within the meaning of the Act, is one difficult to decide. The terms of the Act are absolute, and do not take accounts of quantity or proportion. Strictly speaking therefore the presence of a statutory poison in infinitesimal amount would be legally sufficient to bring a preparation within the scope of the act (Anon (o), 1892/3: 227).

The Society complained that the rigidity of the system allowed some toxic substances to be sold unchecked because they were not on the Poisons Schedule, while even dilute solutions of scheduled substances had to be labelled. Other problems had come to light as the position of chemists and druggists changed. In 1867 of the 13,000 on the register, less than 200 had passed the examination of the Privy Council, although by 1897, 12,080 had passed out of a possible 15,215 chemists. However, a number of limited companies had developed to trade as chemists and these fell outside the scope of the Act (Anon (o), 1899: 13). Between 1868 and 1900 there were two attempts to pass amending legislation, but these were successfully opposed by the Pharmaceutical Society with the support of chemists. The philosophy of the Society to control the distribution of poisons was summed up in 1868,

Any further amendment of the Pharmacy and Poison laws of the country should only be proceeded with by the Government after consulting those who are most deeply interested in the matter and in any case it should ever be borne in mind that the elucidation and proper qualification of the vendor cannot be improved upon as means of protection for 
the public in connection with the sale and dispensing of poisons (Anon (j), 1898: 194)

The policies that emerged in the latter part of the nineteenth century, developed due both to the interests of a strong professional group, and the lack of well defined scientific understanding of the nature of poisons. The Pharmaceutical Society was concerned with improving the professional status of its members through examination and licensing, as well as obtaining control over the scheduling of poisons. It was successful in retaining administration of the Poisons Schedule, due to the reluctance of the government to include any general scientific definition of poisonous substances, and the decision to take a pragmatic course using a list of restricted substances.

\section{Discussion}

This paper has reflected on the status of chemical technologies in response to Kim's (2008) observations that their social entrenchment and inflexibility gives rise to a periodic requirement to enact policy change in uncertain contexts. The need to control the sale of poisons in nineteenth century Britain has been taken as an example of this type of situation. The specific role of the Pharmaceutical Society, which participated in policy debates in favour of their chemist and druggist membership, has been identified as a powerful organisation prepared to put forward strategic argumentation regarding their expertise. This was achieved by making continual statements about a preferred future policy. Such discourse can be understood as an attempt to minimise the risks inherent in complex socio-technical change. Kleinberg (2007) suggests that interpretation of historical texts should place emphasis on uncertainties and interpretations of meaning. Such writings should be viewed as a site of contestation and struggle full of 
'unconscious, unquestioned or implicit assumptions' (Kleinberg, 2007: 114) rather than that of asserted order and clarity of meaning. The case presented here has attempted to analyse rhetorical statements that were made over a period of time in order to counter a general perception that socio-technical policies are essentially an expression of authoritative, objective and certified knowledge. Persistent and attentive communications from the Society eventually culminated in the passage of the Pharmacy Act 1868, legislation which enshrined the role of the Society in its administration. However, achieving this outcome had required adoption of a clear and strategic rhetorical approach in which certain objectives were flexibly altered and reset over time, demonstrating how strategic objectives are pursued in a non-linear manner in temporal terms in a complex socio-technical environment. The competitive, strategic and negotiated aspects to achieving the legitimacy to speak for medical knowledge have also been identified in North America (see Whooley, 2013).

Without insights into the arguments put forward by the Pharmaceutical Society this episode of policy formulation could be interpreted as linear, rational and progressive. Public policy is enacted initially to regulate the sale of one poison, arsenic and then provisions are extended to incorporate a wider list of designated toxic substances. However, the public statements of the Society expose this linear explanation as overly simplistic. The Society had articulated a strategy in the 1840s, prior to the passage of the Arsenic Act, indicating its support for a policy to control sale of certain designated poisons. It had also stated its intention to argue for policy that would not harm the economic interests of its members and would also recognise and support their expertise in administering controls at the point of sale. Public health, it was argued, would be best served through professionalisation of chemists and druggists, raising standards of technical 
expertise and introducing new qualifications. From the point of view of the Pharmaceutical Society, the fact that arsenic became singled out for control hindered the straightforward adoption of their policy aims. Support for the Arsenic Act can therefore be seen as a tactical retreat, forcing longer term goals into temporary abeyance, a hedging approach which served to retain the Society’s influence on policy formulation. Subsequently, between 1851 and the passage of the Pharmacy Act in 1868, the Society returned to its original priorities, restating the strategic objective of retaining control of poisonous substances at the point of sale, distributed by professionals. During this period the Society actively opposed counter suggestions and cooperated with organisations as far as they shared common aims. The relative balance of responsibilities it shared with the Privy Council demonstrates how successful it had become in developing wider social and political recognition of its particular area of expertise. The necessity and flexibility to adapt to changes in political conditions illustrates that, for the Pharmaceutical Society, this episode was a non-linear experience through which it had to negotiate a way towards their preferred outcome. Such non-linearity gives support to Kim’s (2008) concept that widely distributed chemical products are an example of socio-technical complexity. In addition, the fact that the Society had to continue to defend its position after 1868 by opposing suggested changes and by publicising a statement of success indicates that the situation was not a rational handing of power to an expert body, rather than an argumentative position not yet securely won.

\section{Conclusion}

By identifying the strategic intent behind rhetorical discourse, it is possible to review the argumentation that culminated in the Pharmaceutical Society’s invitation to administer the Pharmacy Acts. Following the discourse leads away from conventional interpretations of the 
linearity and rationality of this step, towards understanding the Society's strategic intent, in which long term objectives become temporarily eclipsed by short term compromise. The Pharmaceutical Society maintained a vision of a future situation in which it would enjoy the trust and reputation of a body with professional prowess. However, this is achieved through the twists and turns of actions and responses. This case helps to elucidate issues about the nature of technology policies raised by both Lengwiler (2008) and Millstone (2009). As Lengwiler suggests this nineteenth century discourse firmly argues for recognition of technical expertise as a legitimate authority separate both from common knowledge of either an educated class or the wider public. The necessity to state and restate this position is an iterative process which aims to be persuasive in relation to other powerful groups. This case exposes the pre-conditions for technocracy, which Millstone identifies as an unquestioning acceptance of rationalistic scientific knowledge that would dominate policy during the following century. 


\section{References}

Americ JH and Craig RJ (2004). The rhetoric of a juggernaut: AOL Time Warner's internet policy statement. Prometheus 22 (1): 21-41.

Anon (a) (1844/5) Letter from ‘A Country Member’. Pharmaceutical Journal (4): 175-6.

Anon (b) (1844/5) On the sale of poisons. Pharmaceutical Journal (4): 341.

Anon (c) (1849/50) The sale of poisons. Pharmaceutical Journal (9): 161.

Anon (d) (1844/5) Editorial comment. Pharmaceutical Journal (4): 344.

Anon (e) (1847/8) Editorial comment. Pharmaceutical Journal (7): 142.

Anon (f) (1848/9) Accidental poisoning. Pharmaceutical Journal (8): 260-3.

Anon (g) (1849/50) The sale of poisons, Pharmaceutical Journal (5): 249.

Anon (h) (1852/3) Toxicology. Pharmaceutical Journal (12): 150.Anon (h) (1857/8)

Pharmaceutical Society meeting on the Sale of Poisons Bill, 3rd June, 1857’ Pharmaceutical Journal (17):10.

Anon (i) (1857/8) Editorial comment. Pharmaceutical Journal (17): 417.

Anon (j) (1898) A brief history of poisons legislation in the United Kingdom. Pharmaceutical Journal 4th Series (7): 192.

Anon (k) (1858/9) Sale of poisons bill. Pharmaceutical Journal (18): 483.

Anon (l) (1868/9) The sale of poisons and extension of the Pharmacy Act. Pharmaceutical 
Journal 2nd series (10): 49.

Anon (m) (1869/70) The alleged insufficiency of the Pharmacy Act 1868 to restrict the sale of poisons. Pharmaceutical Journal 2nd series (11): 315.

Anon (n) (1892/3) Death by poison. Pharmaceutical Journal 3rd series (23): 611.

Anon (o) (1892/3) Editorial comment. Pharmaceutical Journal 3rd series (23): 227.

Anon (p) (1899) Report of examinations. Pharmaceutical Journal 4th series (18): 13.

Bartrip P (1992) A “Pennurth of arsenic for rat poison”: The Arsenic Act, 1851 and the prevention of secret poisoning. Medical History (36): 53-69.

Bath FEP (1856) Reprint of a letter to the Times, September, 19th 1856. Pharmaceutical Journal (16): 258.

Byrne D (2005) Complexity, configurations and cases. Theory, Culture and Society 22: 94-111.

Coles AM (2010) Technocratic discourse and technology management: the control of poisons in 19th century Britain. Paper given at 'Managing Knowledge in the Techno-sciences, 1850-2000' conference University of Leeds 5-8 July.

Colingridge D (1980). The Social Control of Technology. London: Pinter

Cillers P (2005) Complexity, deconstruction and relativism. Theory Culture and Society 22: 255267.

Dunmine, PL (2005). Preempting the future: rhetoric and ideology of the future in political discourse. Discourse and Society 16 (4), 481-513. 
Genus A (1995) Walls and bridges: Towards a multi-disciplinary approach to the concept of flexibility. Technology Analysis and Strategic Management 7(3): 287-306.

Genus A (1997) Managing large-scale technology and inter-organsational relations: The case of the Channel tunnel. Research Policy 26: 169-189.

Genus A. and Coles AM (2005) On constructive technology assessment and limitations on public participation in technology assessment. Technology Analysis and Strategic Management (17): 433-443.

Geyer R (2003) Beyond the third way: The science of complexity and the politics of choice. British Journal of Politics and International Relations (5): 237-57.

Hansard (1868a) House of Lords Debate, 18th June, 192 paragraph 1748

Hansard (1868b) House of Commons Debate: Committee, 15th July, 193, paragraph 1217.

Hearn G, Roony B and Mandeville T (2003) Phenomenological turbulence in innovation and knowledge systems. Prometheus (21): 231-244.

Hirsch P M and Gillespie J J (2001) Unpacking path dependence: differential valuations accorded history across disciplines. In Garud R Karnow P (eds) Path Dependency and Creation. New Jersey: Lawrence Erlbaum.

Holloway, S W F (1991) Royal Pharmaceutical Society of Great Britain 1841-1991: A Political and Social History, London: Pharmaceutical Press

Homan PG (2005) The development of community pharmacy. In S Anderson (ed) Making 
Medicines: A Brief History of Pharmacy and Pharmaceuticals. London: Pharmaceutical Press, 115-133 .

Jensen CB (2005) An experiment in performative history: Electronic patient records as a future generating device, Social Studies of Science (35): 241-267.

Jerit J (2008) Issue framing and engagement: Rhetorical strategy in public policy debates. Political Behaviour (50): 1-24.

Kim E-S (2008) Chemical sunset: Technological inflexibility and designing an intelligent precautionary "Polluter Pays" principle. Science Technology Human Values (33): 459-479.

Kleinberg E (2007). Haunting history: Deconstruction and the spirit of revision. History and Theory (46): 113-143.

Lengwiler M (2008) Participatory approaches in science and technology: Historical origins and current practices in critical perspective. Science Technology Human Values ,(33): 186 - 200.

McNally R (2000) Strategic use of "risk" in gene technology: The European rabies eradication programme. In B Adam, U Beck and J Van Loon (eds.) The Risk Society and Beyond: Critical Issues For Social Theory. Sage: London,112-118.

Mackenzie, A (2005) The problem of the attractor: A singular generality between sciences. Social Theory (10): 45-65.

Marland H (1987) The medical activities of mid-nineteenth century chemists and druggists, with special reference to Wakefield and Huddersfield, Medical History (31): 415-439. 
Millstone E (2009) Science, risk and governance: Radical rhetorics and the realities of reform in food safety governance. Research Policy (38): 624-636.

Mulkay M (1993) Rhetorics of hope and fear in the great embryo debate. Social Studies of Science (23): 721-742.

Nowotny H (2005) The increase of complexity and its reduction. Theory Culture and Society (22): 15-31.

Urry J (2005) The complexities of the global. Theory Culture and Society (22): 235-254.

Urry J (2003). Global Complexity. Cambridge: Polity.

Whooley, O (2013) Knowledge in the Time of Cholera: The Struggle over American Medicine in the Nineteenth Century, Chicago: Chicago University Press

Worling PM (2005) Pharmacy in the early modern world (1617-1841). In S Anderson (ed)

Making Medicines: A Brief History of Pharmacy and Pharmaceuticals. London: Pharmaceutical Press, 112-118.

\section{Bibliographic note:}

Dr Anne-Marie Coles is senior lecturer in the Business School at Greenwich University and leader of the Sustainability, Technology and Innovation Research group (STIR). 